\title{
Financial Crises, Unconventional Monetary Policy Exit Strategies, and Agents' Expectations*
}

\author{
Andrew T. Foerster ${ }^{\dagger}$ \\ Federal Reserve Bank of Kansas City
}

December 29, 2011

\begin{abstract}
A Markov switching DSGE model with financial frictions investigates the effects of unconventional monetary policy (UMP) exit strategies. Agents in the model have rational expectations about the probability of financial crises, the probability of a UMP response to crises, and the exit strategy used. Selling off assets quickly produces a doubledip recession; in contrast, a slow unwind generates a smooth recovery. Increasing the probability of a UMP response to crises lowers pre-crisis consumption. The welfare benefits of increasing the probability of UMP may differ ex-ante versus ex-post, as can the preferred exit strategy.
\end{abstract}

${ }^{*}$ The views expressed herein are solely those of the author and do not necessarily reflect the views of the Federal Reserve Bank of Kansas City or the Federal Reserve System. I thank Juan Rubio-Ramirez, Francesco Bianchi, Craig Burnside, Nobuhiro Kiyotaki, Eric Swanson, Stephanie Schmitt-Grohe, and Giuseppe Ferrero for helpful comments, as well as seminar participants at Duke, the Federal Reserve Banks of Richmond, Kansas City, and San Francisco, the Federal Reserve Board, Boston College, Michigan State, McMaster, the Bank of Canada, the 2011 International Conference on Computing in Economics and Finance, the 2011 North American Summer Meetings of the Econometric Society, and the "Conference on Zero Bound on Interest Rates and New Directions in Monetary Policy." Any remaining errors are my own.

${ }^{\dagger}$ Research Department, Federal Reserve Bank of Kansas City, 1 Memorial Drive, Kansas City, MO 64198, www.econ.duke.edu/ atf5/, andrew.foerster@kc.frb.org 


\section{Introduction}

In the fall of 2008, the US economy experienced a financial crisis, marked by a deterioration in financial conditions along with a rapid slowing of real economic activity. In response, the Federal Reserve expanded its purchases of financial assets, injecting additional capital into the economy. The increased demand for financial assets provided by the Federal Reserve helped bolster asset values and alleviate the pressure on financial institutions by lessening the drop in the value of assets on their respective balance sheets. The Federal Reserve accomplished this expansion in asset purchases by instituting a number of new lending facilities, such as expanding its purchases of mortgage backed securities and commercial paper. This response is deemed "unconventional monetary policy" because of the wide range of assets purchased, in contrast to "conventional monetary policy" which typically consists of purchasing short-term Treasuries to manage short-term interest rates. In total, the value of non-Treasuries assets held by the Federal Reserve reached over $\$ 1.5$ trillion. Figure 1 shows the sizeable increase in the total balance sheet, the non-Treasuries portion of the balance sheet, and a measure of interest rate spreads that jumped during the crisis, illustrating the increased level of uncertainty.

An additional feature of the financial crisis and Federal Reserve's balance sheet expansion is that even after the crisis ended and interest rate spreads decreased from their peak, the size of the balance sheet remained elevated. In other words, the financial crisis triggered a start in unconventional monetary policy, but the end of the crisis did not trigger an end in unconventional policy. Rather than unwind its unconventional asset position as spreads decreased, the Federal Reserve maintained its asset position past the end of the crisis, and any exit strategy will be independent of the fall in spreads. Consequently, it remains to be seen how the Federal Reserve will unwind the its balance sheet, and what the effects of this unwind are for the macroeconomy.

In addition to the issue of exit strategy, given that the Federal Reserve intervened with unconventional policy, one concern going forward is how ex- 
pectations about intervention policy during crises affect pre-crisis economic behavior. If economic agents expect the central bank to intervene during crises, this expectation may distort economic outcomes prior to a crisis occurring. During the crisis, concerns about the potentially negative repercussions of precedent-setting, such as reckless risk-taking, provided arguments against using unconventional policy. Even if intervention policy benefits the economy during crises, if setting a precedent of intervention has negative effects during non-crisis times, it may be a poor policy choice to set this precedent. On the other hand, if expectations of intervention ease fears about small probability events and allow credit to flow more freely, then setting a precedent may be an entirely positive policy choice.

Considering of the effects of expectations along with the effects during crises motivates an analysis of the welfare benefits of intervention policy. The main consideration with this welfare analysis is a form of time inconsistency: ex-ante - that is, before a crisis occurs - making intervention more likely could decrease welfare, but ex-post - when a crisis occurs - making intervention more likely could improve welfare. In addition, choosing an exit strategy may depend upon the timing of the decision.

This paper addresses these questions about exit strategies, effects of precrisis expectations, and welfare costs by building a dynamic stochastic general equilibrium (DSGE) model with a financial sector where financial crises occasionally occur, and conditional on a crisis occurring, the central bank may or may not intervene with unconventional policy. If the central bank does intervene, it will not do so forever, but at some point it will unwind its balance sheet, selling off its accumulated assets at a specified rate. Using Markov regime switching, the model allows agents to have rational expectations about transitions between regimes where the central bank intervenes and does not. This framework allows the study of exit strategies after intervention occurs, the effects of expectations on pre-crisis economic activity, and the welfare gain or loss from different policy expectations.

There has been a rapidly growing literature on the implications of financial frictions in the macroeconomy. Many DSGE models, such as Christiano et al. 
(2005) and Smets \& Wouters (2007), do not incorporate a financial sector, and are therefore unable to explain movements associated with the banking system. A standard framework to incorporate a financial sector is to use a financial accelerator model, as developed in Bernanke \& Gertler (1989), Kiyotaki \& Moore (1997), and Bernanke et al. (1999), which allows for frictions in the financial sector that slow the flow of funds from households to firms. Gertler \& Karadi (2010) build upon the financial accelerator literature by incorporating a central bank equipped unconventional monetary policy during crises, and show that intervention can lessen the magnitude of downturns associated with financial crises. Other models that allow for financial frictions include Carlstrom (1997), Kiyotaki \& Moore (2008), Brunnermeier \& Sannikov (2011), Christiano et al. (2010), and Perri \& Quadrini (2011). Shleifer \& Vishny (2010), Cúrdia \& Woodford (2010b), Cúrdia \& Woodford (2010a), Cúrdia \& Woodford (2011), Del Negro et al. (2010), Angeloni et al. (2011), Hilberg \& Hollmayr (2011) consider government responses to crises or shocks in the presence of financial frictions.

Many of the papers that consider government intervention during financial crises lack the expectations and transitions between the intervention and no intervention regimes that are included in this paper. When expectations and transitions are ignored, any change in policy is entirely unexpected and considered permanent. Therefore, without the regime switching introduced in this paper, the effects of exit strategies and pre-crisis expectations have to be ignored as well. Following the rare event literature (Rietz (1988), Barro (2006), Barro (2009), and Gourio (2010)), this paper allows financial crises to occur with a small probability, and agents form expectations over the central bank's decision to intervene conditional upon that rare even occurring. However, as in Barro et al. (2010), the model also allows crises to be persistent - that is, to last several periods before ending - and studies the implications of uncertain crisis duration. This uncertainty over crisis duration may have implications for the magnitude of the drop in real activity: if agents are uncertain about how long asset prices will remain suppressed, the economy may not rebound as quickly as if agents know that the crisis will be brief. Bianchi (2011) consider 
the effects of pre-crisis macroprudential policies, and Chari \& Kehoe (2009) consider ex-ante versus ex-post incentives of government bailouts.

Many recent papers use Markov switching to model expectations over discrete changes in government policy. Perhaps the most widely used application considers changing conventional monetary policy rules, such as Davig \& Leeper (2007), Farmer et al. (2008), Farmer et al. (2009), and Bianchi (2010). With Markov switching, expectations over future policy rules affect current dynamics of the economy. For example, in conventional monetary policy switching, expected changes in the inflation target or response to inflation can affect current inflation. In this paper, the probability of changing to a regime where the central bank intervenes with unconventional policy can affect pre-crisis dynamics, and expectations about exit strategies can affect the initial portion of the crisis. Foerster et al. (2011) develop perturbation methods for Markov switching models, which allow flexibility in the modelling of the regime switching and allow for second-order approximations, which are important for welfare analysis.

The paper proceeds as follows. Section 2 discusses the model, with special emphasis on the financial sector. Section 3 details how the parameters of the economy change according to a Markov Process, and details the transitions between regimes. The response of the economy to crises with and without intervention is discussed in Section 4, as are the effects of different exit strategies. Section 5 analyzes the effects of expectations of crisis policies on the pre-crisis economy. Section 6 discusses the welfare implications of policy announcements, and Section 7 concludes.

\section{Model}

This section describes the basic model, based on that developed in Gertler \& Karadi (2010). It is a standard DSGE model with the addition of a financial sector, which serves as an intermediary between households and nonfinancial firms. The next section describes the regime-switching in detail; this section simply notes which parameters switch. 


\subsection{Households}

The economy is populated by a continuum of households of unit measure. These households consume, supply labor, and save by lending money to financial intermediaries or potentially to the government.

Each household is comprised of a fraction $(1-f)$ of workers and a fraction $f$ of bankers. Each worker earns wages by supplying labor to nonfinancial firms, and each banker owns a financial intermediary that returns its earnings to the household. Bankers become workers with probability $(1-\theta)$, so a total fraction of $(1-\theta) f$ transition to become workers; the same fraction transition from being workers to being bankers, and the probability is independent of duration. Upon exit, bankers transfer their accumulated net worth to the household, and new bankers receive initial funds from the household. Within the household, there is perfect consumption insurance.

The households maximize their lifetime utility function

$$
\mathbb{E}_{0} \sum_{t=0}^{\infty} \beta^{t}\left\{\log \left(C_{t}-h C_{t-1}\right)-\frac{\varkappa}{1+\varphi} L_{t}^{1+\varphi}\right\}
$$

where $\mathbb{E}_{0}$ is the conditional expectations operator, $\beta \in(0,1)$ is the discount factor, $C_{t}$ is household consumption at time $t, h$ controls the degree of habit formation in consumption, $L_{t}$ is household labor supply, $\varkappa$ controls the disutility of labor, and $\varphi$ is the inverse of the Frisch labor supply elasticity.

Households earn income from workers earning a wage $W_{t}$ on their labor supplied $L_{t}$, they receive an amount $\Delta_{t}$ of net profits from financial and nonfinancial firms, which equals profits and banker earnings returned to the household from exiting bankers less some start-up funds for new bankers, and they receive lump sum transfers $T_{t}$. Households save by purchasing bonds $B_{t}$ either from financial intermediaries or the government, these bonds pay a gross real return of $R_{t}$ in period $t+1$. In equilibrium, both sources of bonds are riskless

and hence identical from the household's perspective, so $R_{t}$ is the risk-free rate of return. Households then have income $R_{t-1} B_{t-1}$ from bonds. Consequently, 
the household's budget constraint is given by

$$
C_{t}+B_{t}=W_{t} L_{t}+\Delta_{t}+T_{t}+R_{t-1} B_{t-1}
$$

Using a multiplier $\varrho_{t}$ on (2), the household's optimality conditions are

$$
\begin{gathered}
\left(C_{t}-h C_{t-1}\right)^{-1}-\beta h \mathbb{E}_{t}\left(C_{t+1}-h C_{t}\right)^{-1}=\varrho_{t}, \\
\beta R_{t} \mathbb{E}_{t} \frac{\varrho_{t+1}}{\varrho_{t}}=1, \\
\varkappa L_{t}^{\varphi}=\varrho_{t} W_{t},
\end{gathered}
$$

which are for the marginal utility of conumption, bonds, and disutility of labor.

\section{$2.2 \quad$ Financial Intermediaries}

Financial intermediaries channel funds between the households and nonfinancial firms. Financial intermediaries, indexed by $j$, accumulate net worth $N_{j, t}$ and collect deposits from households $B_{j, t}$. Using these two sources of funding, they purchase claims on non-financial firms $S_{j, t}$ at relative price $Q_{t}$. The intermediaries' balance sheets require that the overall value of claims on nonfinancial firms equals the value of the intermediaries net worth plus deposits:

$$
Q_{t} S_{j, t}=N_{j, t}+B_{j, t}
$$

In period $t+1$ households' deposits made at time $t$ pay a risk-free rate $R_{t}$. The claims on non-financial firms purchased at time $t$, pay out at $t+1$ a stochastic return of $R_{t+1}^{k}$. The evolution of net worth is the difference in interest received from non-financial firms and interest paid out to depositors:

$$
N_{j, t+1}=R_{t+1}^{k} Q_{t} S_{j, t}-R_{t} B_{j, t}=\left(R_{t+1}^{k}-R_{t}\right) Q_{t} S_{j, t}+R_{t} N_{j, t} .
$$

Hence, the intermediary's net worth will grow at the risk-free rate, with any growth above that level being the excess return on assets $\left(R_{t+1}^{k}-R_{t}\right) Q_{t} S_{j, t}$. Faster growth in net worth therefore must come from higher realized interest 
rate spreads $R_{t+1}^{k}-R_{t}$ or an expansion of assets $Q_{t} S_{j, t}$.

Since the evolution in net worth depends on the interest rate spread, a banker will not fund assets if the discounted cost of borrowing exceeds the discounted expected return. The banker's participation constraint is therefore

$$
\mathbb{E}_{t} \beta^{i+1} \frac{\varrho_{t+1+i}}{\varrho_{t}}\left(R_{t+1+i}^{k}-R_{t+i}\right) \geq 0, \text { for } i \geq 0
$$

where $\beta^{i+1} \frac{\varrho_{t+1+i}}{\varrho_{t}}$ is the stochastic discount factor applied to returns in period $t+1+i$. The inequality is a key aspect of the model with financial frictions: without constrained financial intermediaries the participation constraint exactly binds by no arbitrage. In a model with financial frictions, financial intermediaries may be unable to take advantage of positive expected interest rate spreads due to borrowing or leverage constraints.

Each period bankers exit the financial intermediary sector and become standard workers with probability $(1-\theta)$. This probability limits the lifespan of bankers, eliminating their ability to accumulate net worth without bound. If the participation constraint (8) holds, a banker will attempt to accumulate as much net worth as possible upon exit. The banker's objective function is to maximize the present value of their net worth at exit. The expected discounted terminal net worth is then

$$
\begin{aligned}
V_{j, t} & =\mathbb{E}_{t}(1-\theta) \beta \sum_{i=0}^{\infty} \beta^{i} \theta^{i} \frac{\varrho_{t+1+i}}{\varrho_{t}} N_{j, t+1+i} \\
& =\mathbb{E}_{t}(1-\theta) \beta \sum_{i=0}^{\infty} \beta^{i} \theta^{i} \frac{\varrho_{t+1+i}}{\varrho_{t}}\left(\left(R_{t+1+i}^{k}-R_{t+i}\right) Q_{t+i} S_{j, t+i}+R_{t+i} N_{j, t+i}\right)
\end{aligned}
$$

This expression shows that, following from the expression (7) describing growth in net worth, the value of being a financial intermediary is increasing in expected future interest rate spreads, $\left(R_{t+1+i}^{k}-R_{t+i}\right)$, future asset levels $Q_{t+i} S_{j, t+i}$, and the risk-free return on net worth.

Expected terminal net worth depends on a banker's current position by

$$
V_{j, t}=v_{t} Q_{t} S_{j, t}+\eta_{t} N_{j, t}
$$


where the discounted marginal gain from expanding assets, $\nu_{t}$, follows

$$
v_{t}=\mathbb{E}_{t}\left[(1-\theta) \beta \frac{\varrho_{t+1}}{\varrho_{t}}\left(R_{t+1}^{k}-R_{t}\right)+\beta \theta \frac{\varrho_{t+1}}{\varrho_{t}} \frac{Q_{t+1}}{Q_{t}} \frac{S_{j, t+1}}{S_{j, t}} v_{t+1}\right],
$$

and the discounted marginal gain from expanding net worth, $\eta_{t}$, satisfies

$$
\eta_{t}=\mathbb{E}_{t}\left[(1-\theta) \beta \frac{\varrho_{t+1}}{\varrho_{t}} R_{t}+\theta \beta \frac{\varrho_{t+1}}{\varrho_{t}} \frac{N_{j, t+1}}{N_{j, t}} \eta_{t+1}\right]
$$

These expressions show that the terminal net worth is increasing in the expected spread $\left(R_{t+1}^{k}-R_{t}\right)$, and the risk free rate $R_{t}$, implying that expectations about future interest rates affect bankers' expected terminal net worth.

In a frictionless environment, if the expected interest rate spread $\left(R_{t+1}^{k}-R_{t}\right)$ is positive, financial intermediaries want to expand their assets infinitely by borrowing additional funds from the household. To eliminate this possibility, there is a friction that allows, in each period, a banker to divert a fraction $\lambda$ of its assets $Q_{t} S_{j, t}$ back to the household, in which case depositors recover the remaining fraction $(1-\lambda)$ of assets. Consequently, the incentive constraint for the banker requires that the expected value of not diverting to exceed the value of diverting funds:

$$
V_{j, t} \geq \lambda Q_{t} S_{j, t}
$$

The constraint (13) binds so long as $\lambda>v_{t}$, which implies that marginal increases in assets have more benefit to the banker being diverted than as an increase in expected terminal wealth. For the purposes of this paper, this constraint will always bind, which implies, using (10) with (13), that assets are a function of net worth by

$$
Q_{t} S_{j, t}=\phi_{t} N_{j, t}, \text { where } \phi_{t}=\frac{\eta_{t}}{\lambda-v_{t}}
$$

denotes the leverage ratio of the financial intermediary. Since the price $Q_{t}$ and the leverage ratio $\phi_{t}$ are independent of banker-specific characteristics, total intermediary demand is a result of summing over all independent inter- 
mediaries $j$ :

$$
Q_{t} S_{I, t}=\phi_{t} N_{t} .
$$

So the total value of intermediated assets $Q_{t} S_{I, t}$ is equal to the economy's leverage ratio $\phi_{t}$ times aggregate intermediary net worth $N_{t}$. The key feature of this expression is that the total amount of assets supplied by the financial intermediaries is in part determined by their net worth. During financial crises, sharp declines in financial intermediary net worth limit the amount of assets the sector can provide for the economy.

Total net worth $N_{t}$ equals that of existing $N_{e, t}$ plus new bankers $N_{n, t}$. Since bankers exit with probability $(1-\theta)$, existing banker net worth makes up a fraction $\theta$ of the growth in net worth from the previous period,

$$
N_{e, t}=\theta\left[\left(R_{t}^{k}-R_{t-1}\right) \phi_{t-1}+R_{t-1}\right] N_{t-1}
$$

In every period, a fraction $(1-\theta)$ of bankers exit and become workers, transferring their accumulated net worth to the household. At the same time, an identical measure of workers become bankers, and receive an initial level of net worth from the household. Specifically, new bankers receive start-up funds equal to a fraction $\frac{\omega}{1-\theta}$ of the assets of exiting bankers $(1-\theta) Q_{t} S_{t-1}$ :

$$
N_{n, t}=\frac{\omega}{1-\theta}(1-\theta) Q_{t} S_{t-1}=\omega Q_{t} S_{t-1}
$$

Therefore, net worth evolves by

$$
N_{t}=\theta\left[\left(R_{t}^{k}-R_{t-1}\right) \phi_{t-1}+R_{t-1}\right] N_{t-1}+\omega Q_{t} S_{t-1} .
$$

\subsection{Government Assets}

The previous section discussed the financial intermediary sector, and how bankers use their net worth and borrowing from households to purchase claims on nonfinancial firms. Now consider that sometimes the central bank may borrow funds from households and purchase assets. In particular, the government owns claims $S_{g, t}$ on nonfinancial firms at relative price $Q_{t}$, for a total value of 
$Q_{t} S_{g, t}$. Since $Q_{t} S_{I, t}$ is the total value of privately intermediated assets, the total value of all assets in the economy is $Q_{t} S_{t}$, where

$$
Q_{t} S_{t}=Q_{t} S_{I, t}+Q_{t} S_{g, t}
$$

The central bank purchases these assets in a manner similar to private financial intermediaries: by issuing debt to households $B_{g, t}$ at time $t$ that pays the risk free rate $R_{t}$ in period $t+1$. In addition, the central bank's claims on nonfinancial firms earn the stochastic rate $R_{t+1}^{k}$ in period $t+1$. The government then will earn returns equal to $\left(R_{t+1}^{k}-R_{t}\right) B_{g, t}$.

Unlike private financial intermediaries, which are balance sheet constrained because of the constant opportunity to divert a fraction $\lambda$ of their assets, the government does not face a similar moral hazard problem - it always repays its debts. Consequently, the central bank faces no constraints on its balance sheet, it can borrow and lend without limit. However, for every unit of assets that the central bank owns, it pays a resource cost of $\tau$. This resource cost captures any possible inefficiencies from government intervention.

The government's policy rule, discussed in Section 2.7, sets a fraction $\psi_{t}$ of total intermediated assets. That is, it sets its purchases such that

$$
Q_{t} S_{g, t}=\psi_{t} Q_{t} S_{t}
$$

To characterize the full leverage ratio of the economy, first note that using the government share (20) and the private intermediaries' total demand (15) in the decomposition of total assets (19) yields

$$
Q_{t} S_{t}=\phi_{t} N_{t}+\psi_{t} Q_{t} S_{t}
$$

Total funds then depends on intermediary net worth by

$$
Q_{t} S_{t}=\phi_{t}^{c} N_{t}, \text { where } \phi_{t}^{c}=\frac{\phi_{t}}{1-\psi_{t}}
$$

is the total leverage ratio for the economy. By setting $\psi_{t}$, the central bank 
manipulates the total leverage ratio $\phi_{t}^{c}$. If the central bank increases its fraction of supplied assets given a fixed private leverage ratio, the total leverage ratio increases at an increasing rate.

\subsection{Intermediate Goods Firms}

Intermediate goods firms operate in a competitive environment, producing using capital and labor. Firms purchase capital by issuing claims $S_{t}$ to financial intermediaries or the government, and then use the funds from issuing those claims to purchase capital for next period. After production, the firm then pays to repair its depreciated capital and sells its entire capital on the open market. A unit of capital and claim have price $Q_{t}$, so $Q_{t} K_{t}=Q_{t} S_{t}$.

Given a level of capital $K_{t-1}$, the firm decides on labor demand, which pays wage $W_{t}$, and a capital utilization rate $U_{t}$, and produces the intermediate good $Y_{t}^{m}$ using a Cobb-Douglas production function

$$
Y_{t}^{m}=\left(U_{t} \xi_{t} K_{t-1}\right)^{\alpha} L_{t}^{1-\alpha}
$$

and sells this output at price $P_{t}^{m}$. Firms are also subject to changes in a capital quality measure $\xi_{t}$ which evolves according to the process

$$
\log \xi_{t}=\left(1-\rho_{\xi}\left(s_{t}\right)\right) \log \xi_{m}\left(s_{t}\right)+\rho_{\xi}\left(s_{t}\right) \log \xi_{t-1}
$$

where $s_{t}$ indicates a hidden Markov state at time $t$. This Markov process affects the mean of the process $\log \xi_{m}\left(s_{t}\right)$, and persistence around the mean $\rho_{\xi}\left(s_{t}\right)$. As in Merton (1973), the capital quality shock $\xi_{t}$ alters the effective capital stock of the economy $\xi_{t} K_{t-1}$ and thereby exogenously changes the value of capital in the economy. A more detailed description of the Markov Process is in Section 3.

The firm faces no adjustment costs, so period-by-period the firm chooses its labor demand and capital utilization such that

$$
W_{t}=P_{t}^{m}(1-\alpha) \frac{Y_{t}^{m}}{L_{t}}
$$


and

$$
P_{t}^{m} \alpha \frac{Y_{t}^{m}}{U_{t}}=\delta^{\prime}\left(U_{t}\right) \xi_{t} K_{t-1}
$$

where the depreciation rate satisfies $\delta^{\prime}\left(U_{t}\right)>1, \delta^{\prime \prime}\left(U_{t}\right)>1$, and $\delta^{\prime \prime}\left(U_{t}\right) U_{t} / \delta^{\prime}\left(U_{t}\right)=$

$\zeta$. The firm earns zero profits state-by-state, so the return on capital is

$$
R_{t}^{k}=\frac{\left[P_{t}^{m} \alpha \frac{Y_{t}^{m}}{\xi_{t} K_{t-1}}+Q_{t}-\delta\left(U_{t}\right)\right] \xi_{t}}{Q_{t-1}} .
$$

This last expression highlights how changes in the capital quality measure $\xi_{t}$ produce exogenous changes in the return on capital.

\subsection{Capital Producing Firms}

Capital producers are competitive firms that buy used capital from intermediate goods firms, repair depreciated capital, build new capital, and sell it to the intermediate goods firms. Gross investment is the total change in capital

$$
I_{t}=K_{t}-\left(1-\delta\left(U_{t}\right)\right) \xi_{t} K_{t-1}
$$

Net investment is gross investment less depreciation:

$$
I_{t}^{n}=I_{t}-\delta\left(U_{t}\right) \xi_{t} K_{t-1}
$$

Firms face quadratic adjustment costs on construction of new capital but not depreciated capital. They maximize net present value of profits

$$
\mathbb{E}_{0} \sum_{t=0}^{\infty} \beta^{t} \frac{\varrho_{t}}{\varrho_{0}}\left\{\left(Q_{t}-1\right) I_{t}^{n}-f\left(\tilde{I}_{t}^{n} / \tilde{I}_{t-1}^{n}\right) \tilde{I}_{t}^{n}\right\}
$$

where $\tilde{I}_{t}^{n}=I_{t}^{n}+I_{s s}, f(1)=f^{\prime}(1)=0$, and $f^{\prime \prime}(\cdot)=\eta_{i}$. The optimal choice of net investment implies the price of capital is given by

$Q_{t}=1+f\left(\tilde{I}_{t}^{n} / \tilde{I}_{t-1}^{n}\right)+f^{\prime}\left(\tilde{I}_{t}^{n} / \tilde{I}_{t-1}^{n}\right)\left(\tilde{I}_{t}^{n} / \tilde{I}_{t-1}^{n}\right)-\mathbb{E}_{t} \beta \frac{\varrho_{t+i}}{\varrho_{t}} f^{\prime}\left(\tilde{I}_{t+1}^{n} / \tilde{I}_{t}^{n}\right)\left(\tilde{I}_{t+1}^{n} / \tilde{I}_{t}^{n}\right)^{2}$ 


\subsection{Retail Firms}

Retail firms repackage intermediate output $Y_{t}^{m}$ into differentiated products $Y_{f, t}$ which they sell at price $P_{f, t}$, where $f \in[0,1]$ denotes differentiated products. Final output is a CES aggregate of retail firm goods:

$$
Y_{t}=\left(\int_{0}^{1} Y_{f, t}^{\frac{\varepsilon-1}{\varepsilon}} d f\right)^{\frac{\varepsilon}{\varepsilon-1}}
$$

Consumers of the final good use cost minimization; standard optimality conditions imply that demand for good $f$ is a function of the relative price of the good times aggregate demand:

$$
Y_{f, t}=\left(\frac{P_{f, t}}{P_{t}}\right)^{-\varepsilon} Y_{t}
$$

Since retail firms repackage intermediate output, their marginal cost is $P_{t}^{m}$. Firms set their price according to Calvo pricing with indexation: a firm can reoptimize each period with probability $(1-\gamma)$, and with probability $\gamma$ simply index prices with respect to lagged inflation and the parameter $\mu$. A firm optimizing its price at time $t$ maximizes the present value of profits

$$
\max _{P_{f, t}} \sum_{i=0}^{\infty} \gamma^{i} \beta^{i} \frac{\varrho_{t+i}}{\varrho_{t}}\left(\prod_{k=1}^{i} \Pi_{t+k-1}^{\mu} \frac{P_{f, t}}{P_{t+i}}-P_{t+i}^{m}\right) Y_{f, t+i}
$$

subject to demand. The optimal relative price $\tilde{P}_{t}^{*}=P_{t}^{*} / P_{t}$ therefore satisfies:

$$
\sum_{i=0}^{\infty}(\gamma \beta)^{i} \frac{\varrho_{t+i}}{\varrho_{t}}\left(\frac{\varepsilon-1}{\varepsilon}\left(\prod_{k=1}^{i} \frac{\Pi_{t+k-1}^{\mu}}{\Pi_{t+k}}\right)^{1-\varepsilon} \tilde{P}_{t}^{*}-\left(\prod_{k=1}^{i} \frac{\Pi_{t+k-1}^{\mu}}{\Pi_{t+k}}\right)^{-\varepsilon} P_{t+i}^{m}\right) Y_{t+i}=0
$$

Given Calvo pricing with indexation, the evolution of the price level satisfies

$$
1=(1-\gamma) \tilde{P}_{t}^{* 1-\varepsilon}+\gamma\left(\frac{\Pi_{t-1}^{\mu}}{\Pi_{t}}\right)^{1-\varepsilon}
$$


Finally, the domestic rate of absorption $\varsigma_{t}$ is defined by

$$
\varsigma_{t}=\int_{0}^{1}\left(\frac{P_{f, t}}{P_{t}}\right)^{-\varepsilon} d f=(1-\gamma)\left(\tilde{P}_{t}^{*}\right)^{-\varepsilon}+\gamma\left(\frac{\Pi_{t-1}^{\mu}}{\Pi_{t}}\right)^{-\varepsilon} \varsigma_{t-1}
$$

and intermediate output and final output are related by $Y_{t}^{m}=\varsigma_{t} Y_{t}$.

\subsection{Government Policy}

There are two aspects to government policy: standard monetary policy and the unconventional policy rule. Conventional monetary policy sets the nominal interest rate $r_{t}$ according to a Taylor rule

$$
\left(\frac{r_{t}}{r_{s s}}\right)=\Pi_{t}^{\kappa_{\pi}}\left(\frac{Y_{t}}{Y_{t}^{*}}\right)^{\kappa_{y}}
$$

where $r_{s s}$ is the steady state nominal rate, and $\kappa_{\pi}$ and $\kappa_{y}$ control responses to the inflation and output gap, respectively. The nominal and risk-free interest rates satisfy the Fisher equation

$$
R_{t} \mathbb{E}_{t} \Lambda_{t+1}=r_{t} \mathbb{E}_{t} \frac{\Lambda_{t+1}}{\Pi_{t+1}}
$$

The government sets its unconventional asset holding $\psi_{t}$ according to

$$
\psi_{t}=\left(1-\rho_{\psi}\left(s_{t}\right)\right) \psi_{m}\left(s_{t}\right)+\rho_{\psi}\left(s_{t}\right) \psi_{t-1}
$$

where the mean of the process $\psi_{m}\left(s_{t}\right)$ and its persistence $\rho_{\psi}\left(s_{t}\right)$ change according to a Markov Process to be discussed in Section 3.

Finally, the government has a fixed amount of spending $G$ every period, plus it must pay a resource cost $\tau$ on its assets. It finances these via lumpsum taxes and the return from its previously held assets. Consequently, the government's budget constraint is given by

$$
G+\tau \psi_{t} Q_{t} K_{t}=T_{t}+\left(R_{t}^{k}-R_{t-1}\right) B_{g, t-1}
$$




\subsection{Resource Constraint}

The resource constraint requires that output be used for consumption, investment plus capital adjustment costs, and government spending including the resource cost of intervention:

$$
Y_{t}=C_{t}+I_{t}+f\left(\tilde{I}_{t}^{n} / \tilde{I}_{t-1}^{n}\right) \tilde{I}_{t}^{n}+G+\tau \psi_{t} Q_{t} K_{t}
$$

and the economy wide evolution of capital is

$$
K_{t}=\xi_{t} K_{t-1}+I_{t}^{n}-f\left(\tilde{I}_{t}^{n} / \tilde{I}_{t-1}^{n}\right) \tilde{I}_{t}^{n},
$$

reflecting that capital quality shocks affect the accumulation of capital.

\section{Regime Switching and Equilibrium}

This section embeds the core model into a regime switching framework. Parameters in two equations switch according to a Markov process: the exogenous process for capital quality (23) and the unconventional policy rule (36). The next two subsections discuss the switching in these equations, and subsection 3.3 covers the calibration and solution method.

\subsection{Markov Switching in the Capital Quality Process}

The first switching equation is the exogenous process for capital quality (23):

$$
\log \xi_{t}=\left(1-\rho_{\xi}\left(s_{t}\right)\right) \log \xi_{m}\left(s_{t}\right)+\rho_{\xi}\left(s_{t}\right) \log \xi_{t-1} .
$$

The functional form allows for changes in the mean of the process through the term $\xi_{m}\left(s_{t}\right)$, and changes in the persistence $\rho_{\xi}\left(s_{t}\right)$, where $s_{t}$ denotes the state of the Markov Process. Allowing for changes in the mean and the persistence captures a wide variety of possible switching dynamics. As mentioned in Section 2.4, changes in capital quality drive exogenous fluctuations in the value of capital, and significant declines generate a financial crisis. 
The two switching parameters $\xi_{m}\left(s_{t}\right)$ and $\rho_{\xi}\left(s_{t}\right)$ each take on two values, and these values depend upon a common Markov process. Specifically, the values depend upon whether or not the economy is in a financial crisis. If the economy is not in a financial crisis, then the mean of the process is $\xi_{m}^{n}=1$, and the persistence is $0<\rho_{\xi}^{n}<1$, where the superscript $n$ denotes "no crisis." With probability $p_{c}$, the economy experiences a financial crisis, and the mean of the process switches to a lower level $\xi_{m}^{c}<1$, where the superscript $c$ indicates "crisis" and the persistence switches to $\rho_{\xi}^{c}=0$. With probability $p_{e}$, the economy exits the crisis and returns to the "no crisis" mean and persistence.

The dual change in parameters between non-crisis and crisis has two effects. First, when the economy enters a crisis, the crisis mean $\xi_{m}^{c}<1$ implies that the capital quality measure decreases. The crisis persistence $\rho_{\xi}^{c}=0$ implies that the capital quality jumps downward to the lower mean. Second, when the economy leaves a crisis, the mean $\xi_{m}^{n}=1$ implies that the capital quality measure returns to its original level, but the persistence $0<\rho_{\xi}^{n}<1$ implies a gradual reversion to this higher mean. These two features capture the typically rapid entry into financial crises, with a quick transition to a low capital quality, while after the crisis ends the economy takes time to return back to its pre-crisis level.

The transition probabilities also assume an asymmetry between entering into and exiting out of financial crises. The probability $p_{c}$ that a crisis occurs is independent of the probability $p_{e}$ that the economy exits a crisis, and this framework can incorporate a wide variety of timing assumptions. In, for example, Gertler \& Karadi (2010) or Gertler \& Kiyotaki (2010), crises are zero probability events $\left(p_{c}=0\right)$, and if a crisis occurs it is a one-period shock $\left(p_{e}=1\right)$. On the other hand, as in Gertler et al. (2010), crises could be independent events $\left(p_{c}=1-p_{e}\right)$. Most importantly, the probabilities allow agents to expect that crises can occur, and, if a crisis does occur, it can last several quarters. 


\subsection{Markov Switching in Unconventional Policy}

The second switching equation governs unconventional policy (36):

$$
\psi_{t}=\left(1-\rho_{\psi}\left(s_{t}\right)\right) \psi_{m}\left(s_{t}\right)+\rho_{\psi}\left(s_{t}\right) \psi_{t-1}
$$

where again the Markov Switching affects the mean of the process $\psi_{m}\left(s_{t}\right)$ and its persistence $\rho_{\psi}\left(s_{t}\right)$. While an independent Markov process controls the exogenous process for capital quality, the unconventional policy rule depends on a Markov process dependent upon the realization of the exogenous process. This feature captures the fact that, when a crisis occurs, the central bank may or may not intervene, but the onset of a crisis triggers the decision to intervene or not. In other words, the central bank will never begin intervention without a crisis. In addition, the central bank may continue to intervene beyond the end of the crisis.

Prior to a crisis, the central bank sets the mean and persistence of its intervention to $\psi_{m}^{n}=0$ and $0 \leq \rho_{\psi}^{n}<1$, where the superscript $n$ denotes "no intervention." When a crisis occurs, which happens with probability $p_{c}$, the central bank intervenes with unconventional policy with probability $p_{i}$, where $i$ denotes "intervention." If it does not intervene, then the mean and persistence remain $\psi_{m}^{n}$ and $\rho_{\psi}^{n}$, respectively. If the central bank does intervene, it sets the mean of the process to be $0<\psi_{m}^{i}<1$ and persistence to be $\rho_{\psi}^{i}=0$. Once the economy exits from the crisis, intervention stops with probability $p_{s}$, and the mean and persistence return to $\psi_{m}^{n}$ and $\rho_{\psi}^{n}$, respectively.

The Markov switching specification implies that when the central bank intervenes, it always does so by purchasing a fraction $\psi_{m}^{i}$ of total assets. When it does not intervene, it sets the mean to $\psi_{m}^{n}=0$, but the persistence is $0 \leq \rho_{\psi}^{n}<1$. These values imply two features about the no intervention case. First, if $\psi_{t-1}=0$, meaning the central bank previously had no assets, then it will continue to have no assets. Second, if it does have assets, so $\psi_{t-1}>0$, then it will continue to hold assets, but will be decreasing its balance sheet size according to an AR process. Consequently, the parameter $\rho_{\psi}^{n}$ captures the exit strategy after a crisis. If $0<\rho_{\psi}^{n}<1$, when the rule switches from intervention 
to no intervention, there will be a gradual unwind of the accumulated assets. On the other hand, if $\rho_{\psi}^{n}=0$, then when the rule switches to no intervention, then instantly $\psi_{t}=0$, meaning the central bank exits the asset market with an immediate sell-off.

\subsection{Calibration and Model Solution}

Based on the preceding discussion of the switching in the capital quality process and the unconventional policy equation, there are four total regimes. The first regime is "normal times" which has high capital quality and the central bank either holds no assets or unwinds its assets. The second regime, called "crisis without intervention," has low capital quality and the central bank holds no assets or unwinds. The third regime, "crisis with intervention," has low capital quality and the central bank actively holds assets. The fourth regime, "post-crisis with intervention," has high capital quality and the central bank actively holding assets. Table 1 summarizes the switching parameters across these regimes, and Table 2 shows the transition probabilities.

Table 3 shows the baseline calibration. Most of the parameters are standard in the literature, and follow estimates in Primiceri et al. (2006). The transition probabilities and switching parameters introduced in this paper capture various aspects of the recent financial crisis. The unit of time is a quarter. First, following Barro (2006), the probability of crises is $p_{c}=0.005$, implying a two percent chance of a crisis per year. Motivated by Figure 1, which showed interest rate spreads spiking to above $5 \%$ for seven months, the probability of exiting a crisis is $p_{e}=0.5$, implying an expected duration of two quarters. The probability of intervention $p_{i}$ and of intervention stopping $p_{s}$ will vary, but the baseline calibration has $p_{s}=1 / 18$, which, along with the expected crisis duration, implies a total duration of intervention of 20 months before exit begins. Figure 1 shows that the Federal Reserve held unconventional assets beyond the end of the crisis. Alternatively, the central bank could have a shorter or longer expected holding duration of either 12 or 28 total months, in which case $p_{s}=1 / 10$ or $1 / 26$, respectively. 
Following Gertler \& Karadi (2010) and Gertler \& Kiyotaki (2010), among others, the size of the financial crisis is a five percent loss in the effective capital stock, roughly matching the shock to the housing market, so $\xi_{m}^{c}=0.95$, and $\rho_{\xi}^{c}=0.66$ to capture the persistence of the crisis. The magnitude of intervention is $\psi_{m}^{i}=0.06$, which again roughly corresponds to Gertler \& Karadi (2010) and the experience of the US economy. The baseline persistence of intervention in the non-intervention regimes is $\rho_{\psi}^{n}=0.99$, which means that when intervention ends, the central bank unwinds its assets very slowly. An alternate calibration will consider the effects of $\rho_{\psi}^{n}=0$, in which the central bank sells its stock of assets off all at once. Lastly, the benchmark calibration will set the resource cost of intervention at $\tau=0$, which implies no loss of output generated by the central bank holding assets. The welfare calculations of Section 6 will consider $\tau=0.0008$ and $\tau=0.002$.

The described Markov switching DSGE model is solved using the perturbation method of Foerster et al. (2011), which has two important features. First, the method introduces Markov Switching from first principles, which in turn allows for a flexible environment that includes switching that affects the steady state of the economy. Given that the switching equations involve switching means, the economy's regime-specific steady states will differ, a feature perturbation handles easily. In addition, perturbation allows for secondand higher-order approximations, which improve the ability to capture the effects of expectations and for welfare calculations.

\section{Crisis Responses and Exit Strategies}

Having discussed the basic model and the nature of regime switching, this section considers financial crises, the effects of intervention, and exit strategies. Given the Markov switching transition, each regime has uncertain duration; the following results describe a "typical" crisis. In these experiments, agents know the probabilities $\left\{p_{c}, p_{e}, p_{i}, p_{s}\right\}$ that dictate the transitions in the economy. In a typical crisis, the realized durations equal the expected durations: the crisis lasts $1 / p_{e}$ periods, and unwinding of intervention begins $1 / p_{s}$ peri- 
ods after the crisis ends. Given the baseline parameterization of $p_{e}=0.5$ and $p_{s}=1 / 18$, then if the typical crisis begins at $t=0$, it ends in $t=2$, and unwinding beings in $t=20$.

\subsection{Intervention Versus No Intervention}

First, consider the effects of a crisis under a guarantee of intervention $\left(p_{i}=1\right)$ versus no intervention $\left(p_{i}=0\right)$. With guaranteed no intervention, the economy is in the "normal times" regime for $t<0$, experiences a crisis in period $t=0$ when it automatically moves to "crisis without intervention" regime, and then at $t=2$ the crisis ends and the economy moves back to the "normal times" regime. With guaranteed intervention, the economy is in the "normal times" regime for $t<0$, and when a crisis occurs at $t=0$ it moves automatically to the "crisis with intervention regime." Then, at $t=2$, the crisis ends and the economy moves to the "post-crisis with intervention" regime, where it stays until $t=20$, at which time it switches to the "normal times" regime and the intervention is unwound.

Figure 2 depicts the responses to the typical crisis with $p_{i}=0$ and $p_{i}=1$. When a crisis occurs, capital quality drops five percent for the duration of the crisis - two periods in this case - and then returns to its pre-crisis levels. When $p_{i}=0$, the level of intervention remains at zero. The shock to capital quality reduces banker net worth, driving the leverage ratio up, and causing a drop in the price of capital, which creates a financial accelerator effect of further diminishing the banker net worth. Since the financial intermediaries have less net worth, they are unable to borrow funds, driving interest rates down and spreads up, and capital declines with less investment. The increase in spreads lasts two quarters before declining, roughly corresponding to the recent crisis in the US, and in contrast to the one-period spike in spreads generated by a one-period shock. In total, the drop in output exceeds $10 \%$ from its pre-crisis level.

When $p_{i}=1$, the crisis is met by a jump in the level of intervention, which continues for 20 quarters beyond the initial crisis. The additional demand 
for capital provided by the central bank in this circumstance works against the financial accelerator effect: the price of capital drops slightly less, leading banker net worth to drop slightly less, and the leverage ratio and interest rate spreads to increase less than without intervention. The increased ability of the private sector to provide capital, as well as that provided by the central bank, yields a trough in output that is less than $9 \%$ of its pre-crisis levels. So intervention lessens the recession by about 2 percentage points. At $t=20$, the central bank begins to unwind, and does so very gradually, since $\rho_{\psi}^{n}=0.99$ in this case, leading to a smooth, albeit slow, transition of the economy back to its pre-crisis levels.

\subsection{Exit Strategies}

Suppose now that intervention is guaranteed $\left(p_{i}=1\right)$, but that the unwind rate after intervention ends differs. When the unwind rate is slow $\left(\rho_{\psi}^{n}=0.99\right)$, the results comparing intervention versus no intervention showed that the economy transitions slowly but smoothly back to its pre-crisis level. Figure 3 shows the effects of this slow unwind contrasted with the case of a sell-off $\left(\rho_{\psi}^{n}=0\right)$. With a sell-off, the intervention response is identical to the slow unwind case for the intervention period, but at $t=20$, when the economy switches back to the "normal times" regime, the central bank immediately unloads its asset holdings rather then unwinding them over an extended period. There are two main implications of this sell-off: contemporaneous to the sell-off and beforehand through expectations.

When the sell-off occurs at $t=20$, the central bank unloading its assets immediately is effectively a fire sale of assets, which depresses the price of capital. The decline in the price of capital diminishes the net worth of bankers, leading to a decline in interest rates, and a jump in the private leverage ratio and the interest rate spread. Since the central bank no longer provides capital and the loss in net worth decreases the private sector's ability to do so, the rebound in capital slows from a loss in investment, and output drops again, approximately two percentage points. Importantly, all of these responses 
are similar to what occurred during the initial crisis, except that at $t=20$ capital quality has fully recovered. In other words, the sell-off creates a second financial crisis and there is a double-dip recession due exclusively to policy.

The second effect of the policy difference is through expectations. The slow unwind and sell-off policies are identical during the intervention regimes, they only differ once unwind begins. However, expectations of the sell-off versus the slow unwind matter during this period when policies are identical. When agents in the economy expect a sell-off to occur at some future date, they must worry about the crisis but also the double-dip recession. In fact, given household consumption smoothing through habits, they have a stronger incentive to provide more labor and save to smooth consumption through the ensuing double dip. As a consequence, the intial loss in capital when the sell-off is expected is not as dramatic as when the slow unwind is expected, banker net worth is lower, and the private leverage ratio is higher and spreads lower during the intervening period. The initial drop in output from the crisis is also slightly less, implying that, with the sell-off policy, the initial downturn is less severe, but the economy experiences a double-dip recession when the central bank unloads its assets.

\subsection{Holding Duration}

Having discussed the fact that an exit strategy of an immediate sell-off produces slightly better a slightly better outcome through the expectations channel but creates a double-dip recession when the sell-off occurs, it is important to consider the holding duration as well as the possibility for a sell-off that is neither immediate but not very slow. Figure 4 shows the responses of output to the baseline duration of 20 total quarters versus the alternatives of a shorter or longer holding time, at 12 or 28 quarters, respectively. For each duration, the figure shows the responses to both the slow unwind $\left(\rho_{\psi}^{n}=0.99\right)$ and the sell off $\left(\rho_{\psi}^{n}=0\right)$ previously considered, but also a fast unwind $\left(\rho_{\psi}^{n}=0.5\right)$.

Changing the expected holding duration produces similar responses to the baseline duration, but with differences in magnitude. For all durations, the 
slow unwind produces a gradual recovery in output to its pre-crisis level, and the sell-off produces an initial drop that is not quite as large but generates a double-dip recession when the central bank exits from its asset position. With a shorter holding duration, the difference in the trough of output between the slow unwind and sell-off is larger than for the baseline duration, reflecting the incentive for households to smooth consumption from habits described in the previous subsection. The size of the double-dip recession decreases with duration: selling-off assets soon after the crisis with a still-weak economy leads to larger negative effects. The sell-off after the longer holding duration still produces the double-dip recession, however.

In addition to the change in duration, the fast unwind case is a mixture between the slow unwind and the sell-off cases. With the fast unwind, the central bank exits quickly, but not immediately. The result, for all three expected durations, is a double-dip that is less immediate but has the same size of trough. Consequently, selling off assets quickly does still produce a double-dip recession, but a more gradual one that simply delays the recovery.

\section{Pre-Crisis: Effects of Expectations}

The previous section focused on the effects of intervention and exit strategies during crises, this section examines the effects of expectations of intervention and exit strategies during non-crisis times. The Markov switching framework established in Section 3 gives agents expectations that crises can occur, as well as expectations about the probability of intervention by the central bank, and the duration of intervention and exit strategy if intervention does occur. These expectations affect prices and quantities before crises occur. Consequently, this section examines how the stochastic steady state of the economy associated with the "normal times" regime changes as the probability of intervention conditional on a crisis increases from $p_{i}=0$ to $p_{i}=1$, and the implications of the expected exit strategy.

Foerster et al. (2011) show that, in general, economies with Markov switching that affects the steady state of the economy are not certainty equivalent, 
which implies that the stochastic steady state associated with each regime depends upon probability distributions across future regimes. In addition, the perturbation method allows a second-order approximation to the solution, and this higher-order expansion can provide more accurate descriptions of how the stochastic steady state for each regime varies. An alternative explanation of the "normal times" regime-conditional stochastic steady state is that it is the average over a long simulation of the economy, where agents expect that crises can occur and have certain expectations about intervention probabilities and exits, but ex-post in the simulation no crises occur.

\subsection{Changes in Pre-Crisis Stochastic Steady State}

In the baseline parameterization, agents perceive the probability of crises to be $p_{c}=0.005$, the exit probability to be $p_{e}=0.5$, and the probability of stopping intervention to be $p_{s}=1 / 18$. Figure 5 shows the percent change in the "normal times" stochastic steady state relative to a benchmark economy where $p_{c}=0$, meaning agents do not expect crises, and hence expectations about intervention policy are irrelevant.

Consider the baseline parameterization with $p_{c}=0.005$ but $p_{i}=0$, so intervention policy is irrelevant and hence the slow unwind and sell-off cases are identical. Moving from an economy where agents do not expect crises $\left(p_{c}=0\right)$, to one where they expect crises without intervention has two main implications. Households, on the one hand, have an incentive to precautionary save in order to smooth consumption during times of crises. In the stochastic steady state, this incentive increases household savings, boosting up capital accumulation and raising output and consumption. On the other hand, crises bring poor interest rate realizations for bankers, who will supply more net worth, have lower leverage, and consequently create a lower amount of capital for the economy, leading to lower output and consumption. In the aggregate, the latter of these effects dominates: the economy with crises has $0.75 \%$ lower capital, $0.445 \%$ lower output, and $0.285 \%$ lower consumption than would be realized in an economy that never experienced crises. 
Now, as $p_{i}$ increases from 0 to 1 , agents expect intervention with a higher probability. Since intervention dampens the effects of crises, increasing the probability of intervention erodes household's precautionary incentive, lowering capital and output, but raises capital and output by favorable interest rate conditions for bankers. In aggregate, as $p_{i}$ increases, consumption declines, but capital and output increase if the sell-off exit strategy is used, but decline if the slow unwind is in place. Consumption also declines more for the slow unwind case than the sell-off, which, since a sell-off produces a double-dip recession, gives more incentive for households to save and boost consumption.

\subsection{Expectations and Habits}

To highlight the impact of the opposing channels, households' precautionary savings versus bankers' interest rates, and the effects of expectations of policy, Figure 6 contrasts the change in the "normal times" stochastic steady state that prevails under the baseline calibration with habits $(h=0.815)$ with that of no habits $(h=0)$. In the no habits case, the households have significantly lower incentive to precautionary save, since their smoothing motive is diminished. As a result, the no habits case has capital, output, and consumption significantly lower, as the lack of precautionary motive lessens the buildup of household savings. As the probability of intervention $p_{i}$ increases, the main effect is to improve the expected spread, which, in equilibrium, leads to lower leverage and higher banker net worth.

\section{Welfare Calculations}

Having considered the effects of policy announcements and expectations during and before crises, this section turns to evaluating the overall welfare gains or losses from different policy announcements. In particular, Section 4 discussed the fact that guaranteed intervention had benefits relative to no intervention during crises, since intervention helps bolster the economy and alleviate the crisis. However, there was a slight trade-off depending upon the exit strategy: 
the immediate sell-off case produced a slightly lower drop in output and consumption, but upon exit, the economy experienced a double-dip recession. In addition, in Section 5, the effects of increasing the probability of intervention had negative effects on pre-crisis consumption. Since crises are rare events, whether or not the continual loss in consumption caused by increasing the chance of intervention outweighs the benefits of intervention during the crises is ultimately a welfare question.

Importantly, in addition to the probability of intervention and the exit strategy considered, welfare costs will be affected by two factors. First, the resource $\operatorname{cost} \tau$ of central bank intermediation will matter for welfare in that, if the cost is high, then a larger portion of output is lost, which may lower welfare. Second, the timing of the calculation matters for welfare costs. Specifically, the household's gain or loss in welfare from different policies will depend upon whether they are experiencing a crisis or not. In other words, the ex-ante welfare costs measure the willingness to pay for intervention before a crisis, while the ex-post welfare costs measure willingness to pay when a crisis occurs.

For ex-ante and ex-post welfare, the welfare measure used is the percentage increase in expected lifetime consumption under guaranteed no intervention that would make households indifferent between the increase in consumption and an policy of a given probability of intervention and exit strategy. Positive welfare measures indicate that intervention is welfare-increasing, since households need additional consumption under the given specification to mimic positive intervention probabilities. Negative welfare measures then imply intervention is welfare-decreasing, as households are willing to give up consumption rather than have positive intervention probabilities.

A second-order expansion to the value function formulation of household preferences (1) allows for accurate welfare measures that incorporate both the effects of crises and the effects of expectations in generating differences in the "normal times" stochastic steady state. 


\subsection{Welfare and the Resource Cost}

Figure 7 depicts the change in the welfare measure as the resource cost $\tau$ and the intervention probability $p_{i}$ change. The top panel shows the baseline case, when $\tau=0$, which corresponds to no efficiency loss from intermediation, the second and third panels show $\tau=.0008$ and $\tau=.002$, respectively. Each panel shows the welfare measure in consumption units for a given intervention probability, both with the slow unwind $\left(\rho_{\psi}^{n}=.99\right)$ and the fast sell-off $\left(\rho_{\psi}^{n}=0\right)$ cases. In addition, they compare welfare when the economy is in the "normal times" regime versus when the economy has experienced a crisis but before realization of the intervention outcome.

The first panel shows that, when $\tau=0$, increases in intervention probability are welfare improving in both the crisis and pre-crisis scenarios. Since there is no resource cost of intervention, and given the magnitude of drops in output and consumption relative to the change in pre-crisis consumption, having intervention is welfare improving. It is interesting to note that the slow unwind exit strategy dominates the fast sell-off strategy in both ex-ante and ex-post circumstances. Since the slow unwind tended to smooth output after crises, this fact implies that agents place emphasis on avoiding the double-dip recession that the sell-off can produce. In addition, conditional on an exit strategy, the benefit from having positive intervention probability is higher once a crisis occurs.

The second and third panels change the implications of intervention. In the second panel, when $\tau=.0008$, the results about the type of intervention and timing change. For both types of exit strategy, the welfare benefits of increasing the intervention probability are negative when the economy is in the "normal times" regime, and positive when the economy enters a crisis. This case suggests that there may be a type of time-inconsistency in the optimal intervention policy. Before a crisis, it households prefer no intervention because of the distortions caused by this guarantee and the resource cost of intervention, but when a crisis occurs, increasing the probability of intervention is welfare improving. Further, conditional upon intervention, the welfarepreferred exit strategy changes from preferring a sell-off $e x$-ante to preferring 
a slow unwind ex-post.

The third panel has $\tau=.002$, when the welfare benefits are negative for all the cases, meaning increasing the probability of intervention is welfare decreasing. This fact holds true regardless of the exit strategy used and the timing. Further, the ex-post welfare losses are higher, and the losses are higher when the exit strategy is to unwind assets slowly. Both of these results stem from the relatively high resource cost of intervention: when intervention is costly in terms of output, there is a welfare loss from intervention, especially when a crisis occurs - because intervention is immediate - and welfare losses are higher when the intervention takes longer to unwind.

The different levels of the resource cost dictate which policy environment is best from a welfare perspective. Importantly, under the $\tau=0.0008$ parameterization for both types of crises, the better rule in terms of welfare changed ex-ante versus ex-post. Prior to a crisis occurring, positive intervention probabilities are welfare decreasing, and the better rule is the fast unwind, but when a crisis occurs positive probabilities are welfare increasing, and the welfare preferred rule is the slow unwind. These changes between the ex-ante versus ex-post welfare implications suggest that there may be a time-inconsistency in optimal policy and hence commitment may be difficult.

\subsection{Welfare and Holding Duration}

Figure 7 shows that the differences between the ex-ante and ex-post welfare measures when $\tau=0.0008$ are fairly robust to holding duration. The figure uses $\tau=0.0008$, and now the probability of stopping varies from $p_{s}=1 / 18$ to the shorter holding duration $p_{s}=1 / 10$ and the longer duration $p_{s}=1 / 26$ considered in the crises responses of Figure 4. As noted previously, when the expected duration is 20 quarters, then increasing the intervention probability increases welfare ex-post, and the dominate exit strategy is the slow unwind; whereas increase the probability decreases welfare ex-ante and the dominant exit strategy is the sell-off.

When the expected holding duration is increased to 28 quarters, the results 
hardly change. When the duration is shorter, at 12 quarters, the main difference is the negativity of the ex-post sell-off welfare measure. In this case, even when a crisis is occurring, the economy is better off with no intervention than with intervention, because the intervention period is so short and is followed by a sell-off of assets that creates a double-dip recession. In other words, agents would rather the central bank not intervene than intervene but exit rapidly and after a short period.

\section{Conclusion}

This paper used a model of unconventional monetary policy along with regime switching to study the effects of exit strategies and agents pre-crisis expectations. After intervention, if the central bank exits its unconventional policy with a sell-off, the economy experiences a double-dip recession. In addition, increasing the probability of intervention during crises causes distortions in pre-crisis activity by altering agents' expectations; in particular, pre-crisis stochastic steady state consumption falls as the intervention probability increases. Finally, the welfare benefits of increasing the probability of intervention can raise or lower welfare, and that the timing of the welfare calculation matters as well as the type of exit strategy used.

One interesting avenue for future research is make the probability and magnitude of intervention endogenous and dependent on the extent of the crisis. This paper assumed fixed crisis magnitudes, levels of intervention, and probabilities. Larger crises presumably have a higher probability and levels of intervention. In addition, the probability of crises is fixed and exogenous; moral hazard could be captured in the model by having a state-dependent probability of crisis. Since expectations about future intervention probabilities and exit strategies affect the pre-crisis state, policy declarations could serve to increase or decrease the probability of crises. Similarly, the probability the central bank starts to unwind its balance sheet may depend upon how quickly the economy rebounds after the crisis. Finally, this paper has focused on a given class of policy, optimal policy within this class is left for future work. 


\section{References}

Angeloni, I., Faia, E., \& Winkler, R. 2011. Exit Strategies. Kiel Institute Working Paper.

Barro, R. 2006. Rare Disasters and Asset Markets in the Twentieth Century. Quarterly Journal of Economics, 121(3), 823-866.

Barro, R. 2009. Rare Disasters, Asset Prices, and Welfare Costs. American Economic Review, 99(1), 243-264.

Barro, R., Nakamura, E., Steinsson, J., \& Ursua, J. 2010. Crises and Recoveries in an Empirical Model of Consumption Disasters. NBER Working Paper, 15920.

Bernanke, B., \& Gertler, M. 1989. Agency Costs, Net Worth, and Business Fluctuations. American Economic Review, 79(1), 14-31.

Bernanke, B., Gertler, M., \& Gilchrist, S. 1999. The Financial Acelerator in a Quantitative Business Cycle Framework. Handbook of Macroeconomics, 1, 1341-1393.

Bianchi, F. 2010. Regime Switches, Agents' Beliefs, and Post-World War II US Macroeconomic Dynamics. Working Paper.

BiAnchi, J. 2011. Overborrowing and Systemic Externalities in the Business Cycle. American Economic Review, 101(7), 3400-3426.

Brunnermeier, M., \& Sannikov, Y. 2011. A Macroeconomic Model with a Financial Sector. Working Paper.

Carlstrom, C.and Fuerst, T. 1997. Agency Costs, Net Worth, and Business Fluctuations: A Computable General Equilibrium Analysis. American Economic Review, 87(5), 893-910.

Chari, VV, \& Kehoe, P. 2009. Bailouts, Time Inconsistency and Optimal Regulation. Federal Reserve Bank of Minneapolis Staff Report. 
Christiano, L., Eichenbaum, M., \& Evans, C. 2005. Nominal Rigidities and the Dynamic Effects of a Shock to Monetary Policy. Journal of Political Economy, 113(1), 1-45.

Christiano, L., Motto, R., \& Rostagno, M. 2010. Financial Factors in Economic Fluctuations. ECB Working Paper, 1192.

Cúrdia, V., \& Woodford, M. 2010a. Conventional and Unconventional Monetary Policy. Federal Reserve Bank of St. Louis Review, 92(4), 229-264.

Cúrdia, V., \& Woodford, M. 2010b. Credit Spreads and Monetary Policy. Journal of Money, Credit and Banking, 42(S1), 3-35.

Cúrdia, V., \& Woodford, M. 2011. The Central Bank Balance Sheet as an Instrument of Monetary Policy. Journal of Monetary Economics, 58(1), $54-79$.

Davig, T., \& Leeper, E. 2007. Generalizing the Taylor Principle. American Economic Review, 97(3), 607-635.

Del Negro, M., Eggertsson, G., Ferrero, A., \& Kiyotaki, N. 2010. The Great Escape? A Quantitative Evaluation of the Fed's Non-Standard Policies. Federal Reserve Bank of New York Staff Report, 520.

Farmer, R, Waggoner, D., \& Zha, T. 2008. Minimal State Variable Solutions to Markov-Switching Rational Expectations Models. Journal of Economic Dynamics and Control, 35(12), 2150-2166.

Farmer, R, Waggoner, D., \& Zha, T. 2009. Understanding MarkovSwitching Rational Expectations Models. Journal of Economic Theory, 144(5), 1849-1867.

Foerster, A., Rubio-Ramirez, J., Waggoner, D., \& Zha, T. 2011. Perturbation Methods for Markov Switching Models. Mimeo.

Gertler, M., \& Karadi, P. 2010. A Model of Unconventional Monetary Policy. Journal of Monetary Economics, 58(1), 17-34. 
Gertler, M., \& Kiyotaki, N. 2010. Financial Intermediation and Credit Policy in Business Cycle Analysis. Handbook of Monetary Economics, 3, $547-599$.

Gertler, M., Kiyotaki, N., \& Queralto, A. 2010. Financial Crises, Bank Risk Exposure and Government Financial Policy. Working Paper.

Gourio, F. 2010. Disasters Risk and Business Cycles. American Economic Review, Forthcoming.

Hilberg, B., \& Hollmayr, J. 2011. Asset Prices, Collateral and Unconventional Monetary Policy in a DSGE Model. ECB Working Paper, 1373.

Kiyotaki, N., \& Moore, J. 1997. Credit Cycles. Journal of Political Economy, 105(2), 211-248.

Kiyotaki, N., \& Moore, J. 2008. Liquidity, Business Cycles, and Monetary Policy. Working Paper.

Merton, R.C. 1973. An Intertemporal Capital Asset Pricing Model. Econometrica, 41(5), 867-887.

Perri, F., \& Quadrini, V. 2011. International Recessions. NBER Working Paper, 17201.

Primiceri, G., Schaumburg, E., \& Tambalotti, A. 2006. Intertemporal Disturbances. NBER Working Paper, 12243.

Rietz, T. 1988. The Equity Risk Premium: A Solution. Journal of Monetary Economics, 22(1), 117-131.

Shleifer, A., \& Vishny, R.W. 2010. Asset Fire Sales and Credit Easing. American Economic Review, 100(2), 46-50.

Smets, R., \& Wouters, F. 2007. Shocks and Frictions in US Business Cycles: a Bayesian DSGE Approach. American Economic Review, 97(3), 586-606. 
Figure 1: Federal Reserve's Balance Sheet

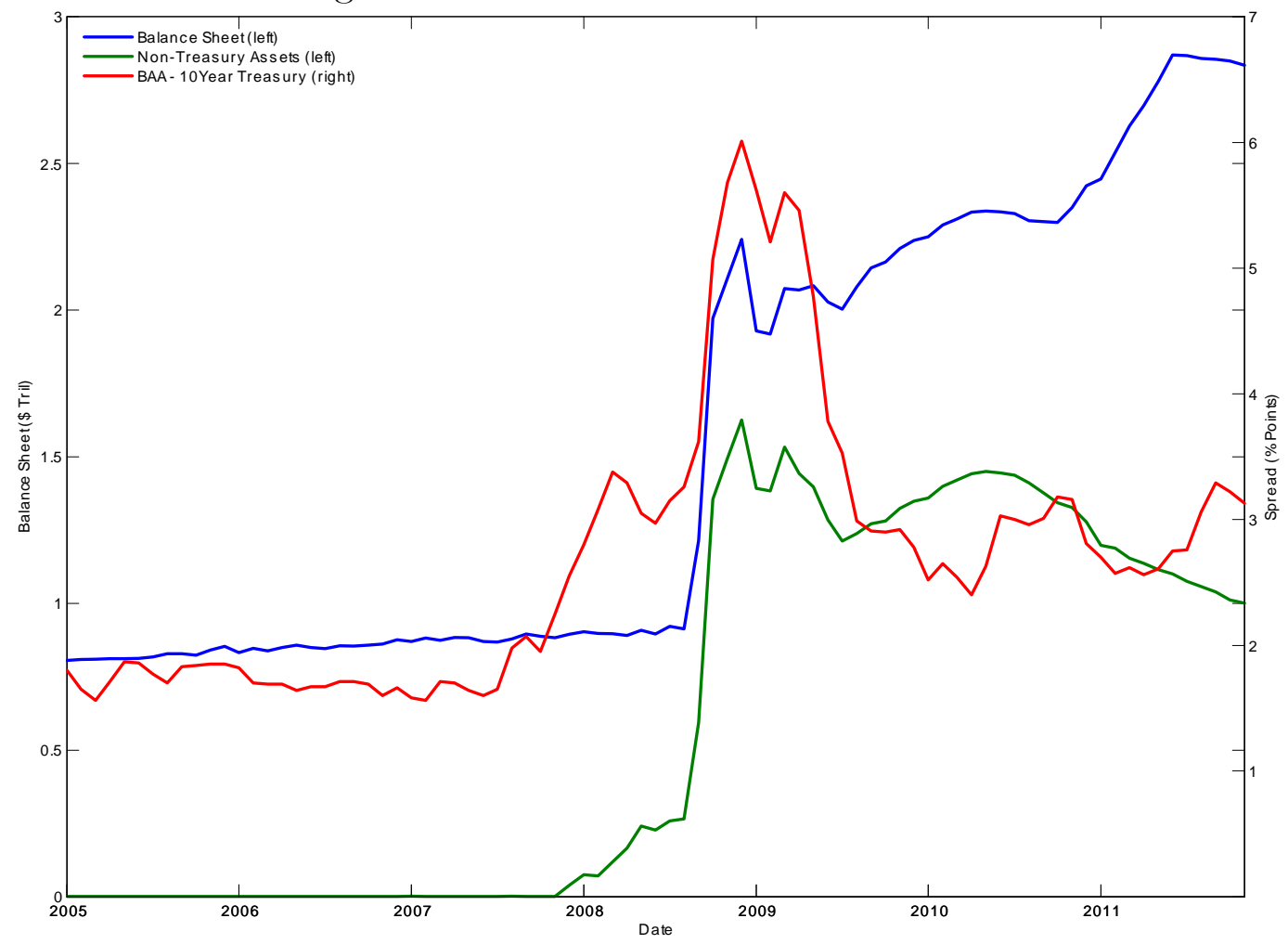

Table 1: Markov Switching Parameters

\begin{tabular}{clcccc}
\hline \hline$s_{t}$ & $\xi_{m}\left(s_{t}\right)$ & $\rho_{\xi}\left(s_{t}\right)$ & $\psi_{m}\left(s_{t}\right)$ & $\rho_{\psi}\left(s_{t}\right)$ \\
\hline 1$)$ & "Normal" & 1 & $\rho_{\xi}^{n}$ & 0 & $\rho_{\psi}^{n}$ \\
$2)$ & "Crisis without Intervention" & $\xi_{m}^{c}$ & 0 & 0 & $\rho_{\psi}^{n}$ \\
$3)$ & "Crisis with Intervention" & $\xi_{m}^{c}$ & 0 & $\psi_{m}^{i}$ & 0 \\
$4)$ & "Post-Crisis with Intervention" & 1 & $\rho_{\xi}^{n}$ & $\psi_{m}^{i}$ & 0
\end{tabular}

Table 2: Markov Switching Probabilities

\begin{tabular}{|c|c|c|c|c|c|}
\hline & & & $s_{t+}$ & & \\
\hline & & 1 & 2 & 3 & 4 \\
\hline & 1 & $1-p_{c}$ & $p_{c}\left(1-p_{i}\right)$ & $p_{c} p_{i}$ & 0 \\
\hline$s_{t}$ & 2 & $p_{e}$ & $1-p_{e}$ & 0 & 0 \\
\hline & 3 & $p_{e} p_{s}$ & 0 & $1-p_{e}$ & $p_{e}\left(1-p_{s}\right)$ \\
\hline & 4 & $\left(1-p_{c}\right) p_{s}$ & 0 & $p_{c}$ & $\left(1-p_{c}\right)\left(1-p_{s}\right)$ \\
\hline
\end{tabular}


Table 3: Benchmark Parameterization

\begin{tabular}{l|l|l}
\hline \hline Parameter & Description & Value \\
\hline$\beta$ & Discount Factor & 0.99 \\
$h$ & Degree of Habit Persistence & 0.815 \\
$\varkappa$ & Disutility of Labor & 3.409 \\
$\varphi$ & Inverse Frisch Elasticity of Labor & 0.276 \\
$\lambda$ & Divertable Fraction of Banker Assets & 0.381 \\
$\omega$ & Transfer to New Bankers & 0.002 \\
$\theta$ & Survival Rate of Bankers & 0.972 \\
$\alpha$ & Capital Share & 0.33 \\
$\bar{U}$ & Steady State Capital Utilization & 1.00 \\
$\bar{\delta}$ & Steady State Depreciation & 0.025 \\
$\zeta$ & Elasticity of Depreciation to Utilization & 7.2 \\
$\eta_{i}$ & Inverse Elasticity of Net Invest. to Capital Price & 1.728 \\
$\varepsilon$ & Elasticity of Substitution Between Final Goods & 4.167 \\
$\gamma$ & Probability of No Optimization of Prices & 0.779 \\
$\mu$ & Degree of Price Indexation & 0.241 \\
$\bar{g}$ & Fraction of Steady State Output for Government & 0.2 \\
$\kappa_{\pi}$ & Response of Interest Rate to Inflation & 2.043 \\
$\kappa_{y}$ & Response of Interest Rate to Output Gap & 0.5 \\
$p_{c}$ & Probability of a Crisis Occuring & 0.005 \\
$p_{e}$ & Probability of Exiting a Crisis & 0.5 \\
$p_{s}$ & Probability of Intervention Stopping & $1 / 18$ \\
$\xi_{m}^{c}$ & Capital Quality During Crises & 0.95 \\
$\rho_{\xi}^{n}$ & Capital Quality Persistence after Crises & 0.66 \\
$\psi_{m}^{i}$ & Central Bank Intervention Level & 0.06 \\
$\rho_{\psi}^{n}$ & Rate of Central Bank Exit & 0.99 \\
$\tau$ & Resource Cost of Intervention & 0 \\
& &
\end{tabular}


Figure 2: Responses Under a Guarantee
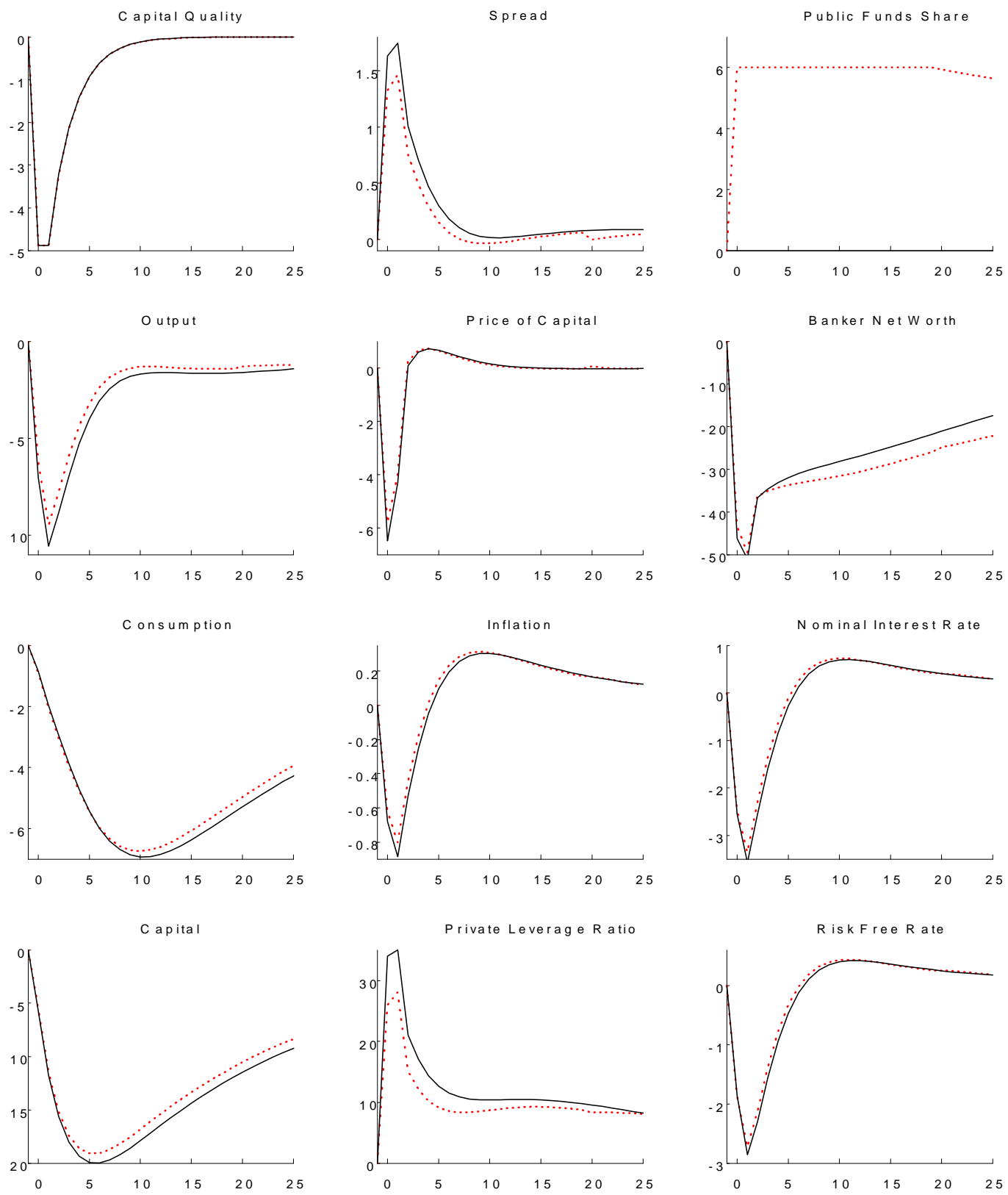

Intervene

No Intervene 
Figure 3: Exit Strategies: Slow Unwind versus Sell-Off
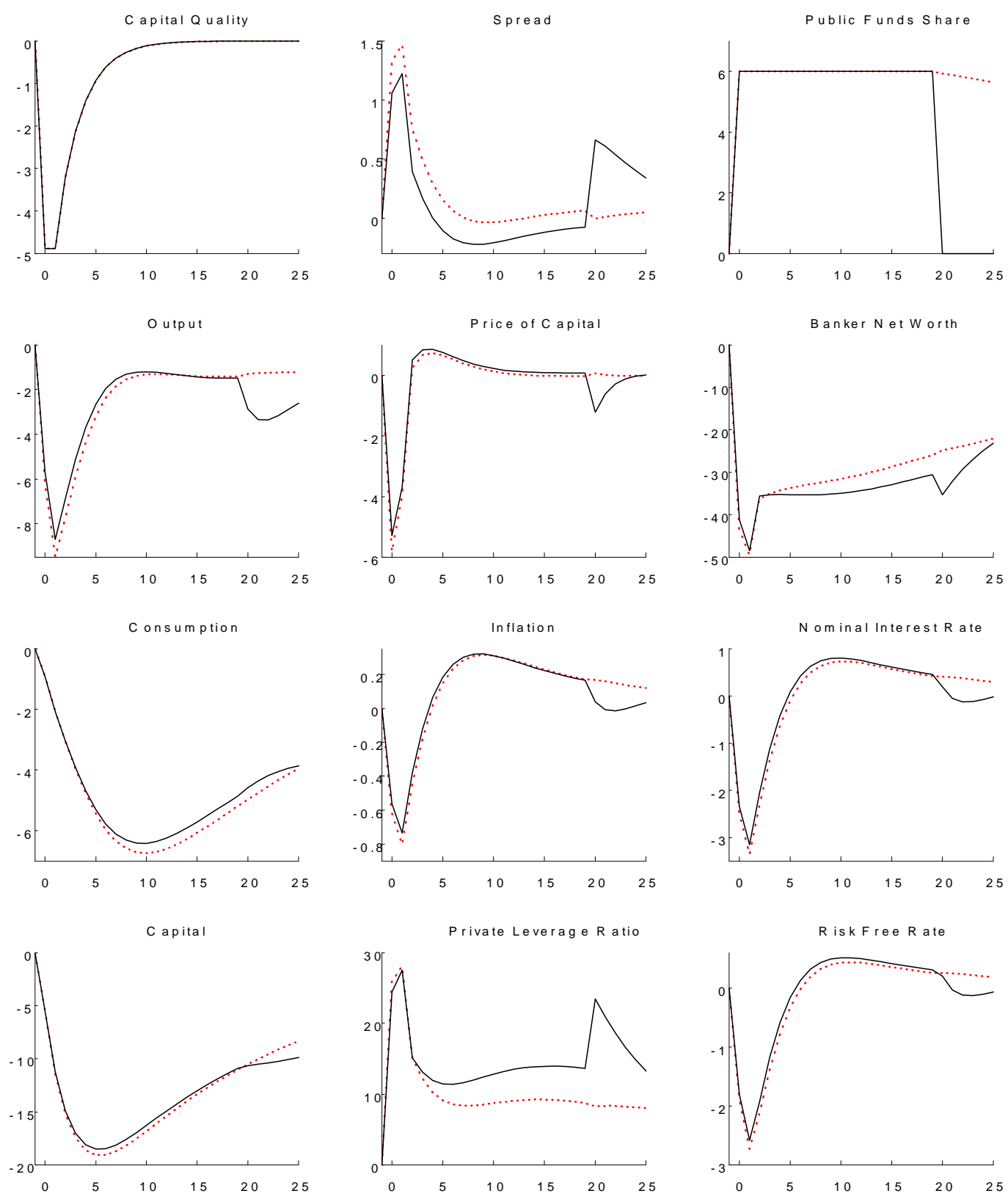
Figure 4: Output Responses to Holding Durations and Exit Strategies
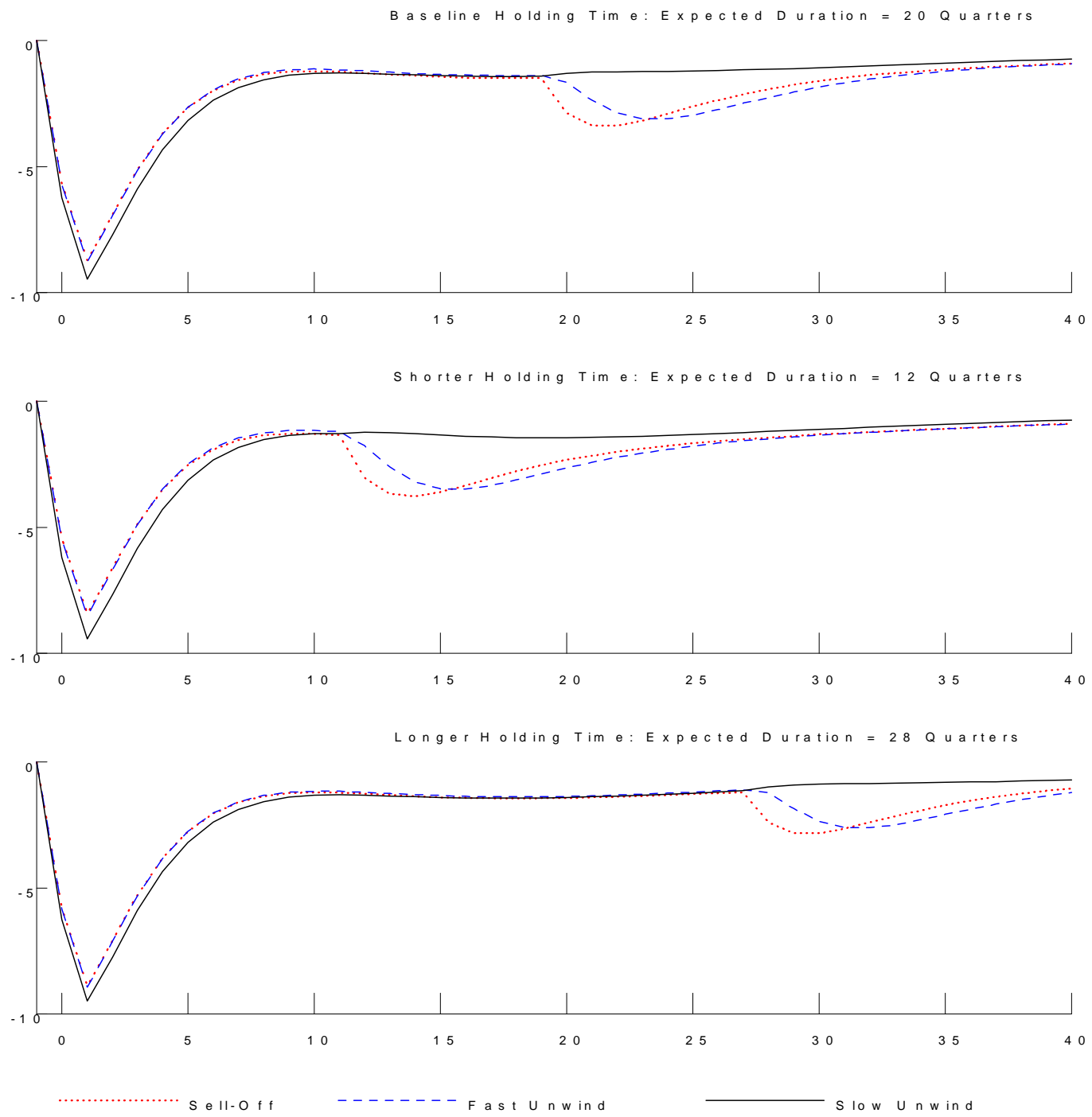
Figure 5: Effects of Expectations
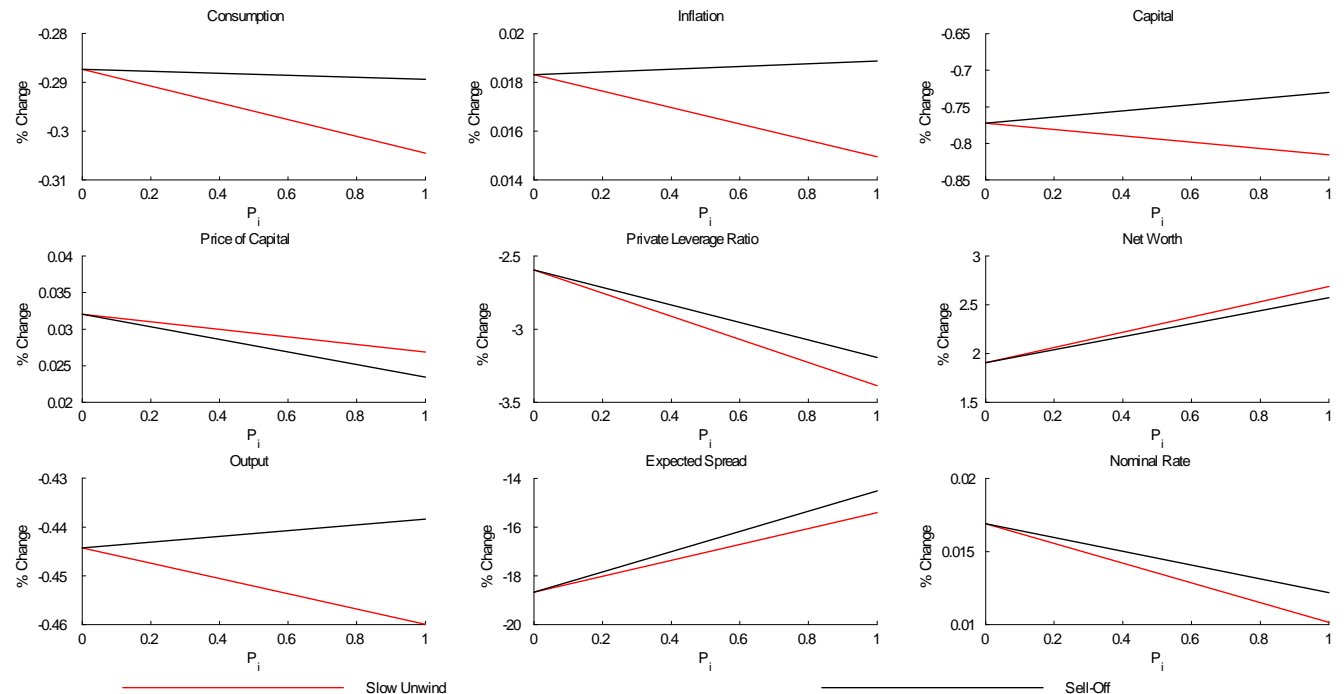

Figure 6: Effects of Expectations and Impact of Habits
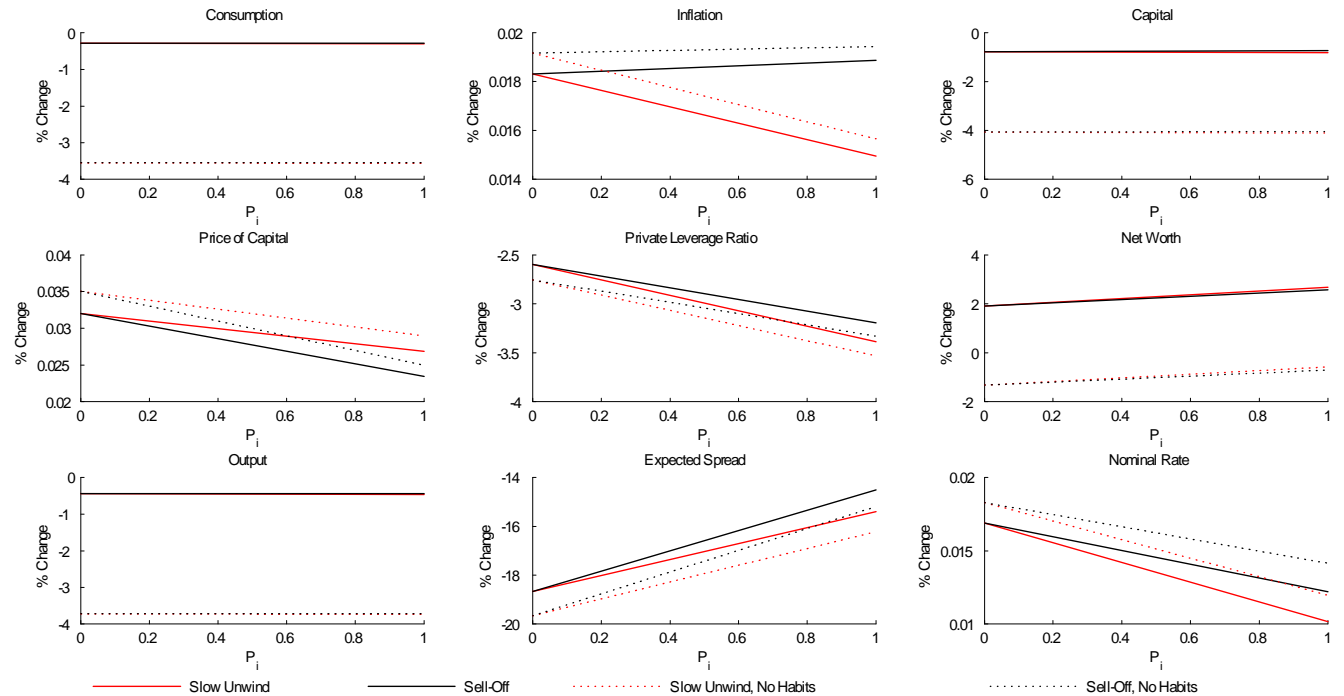
Figure 7: Welfare and the Resource Cost
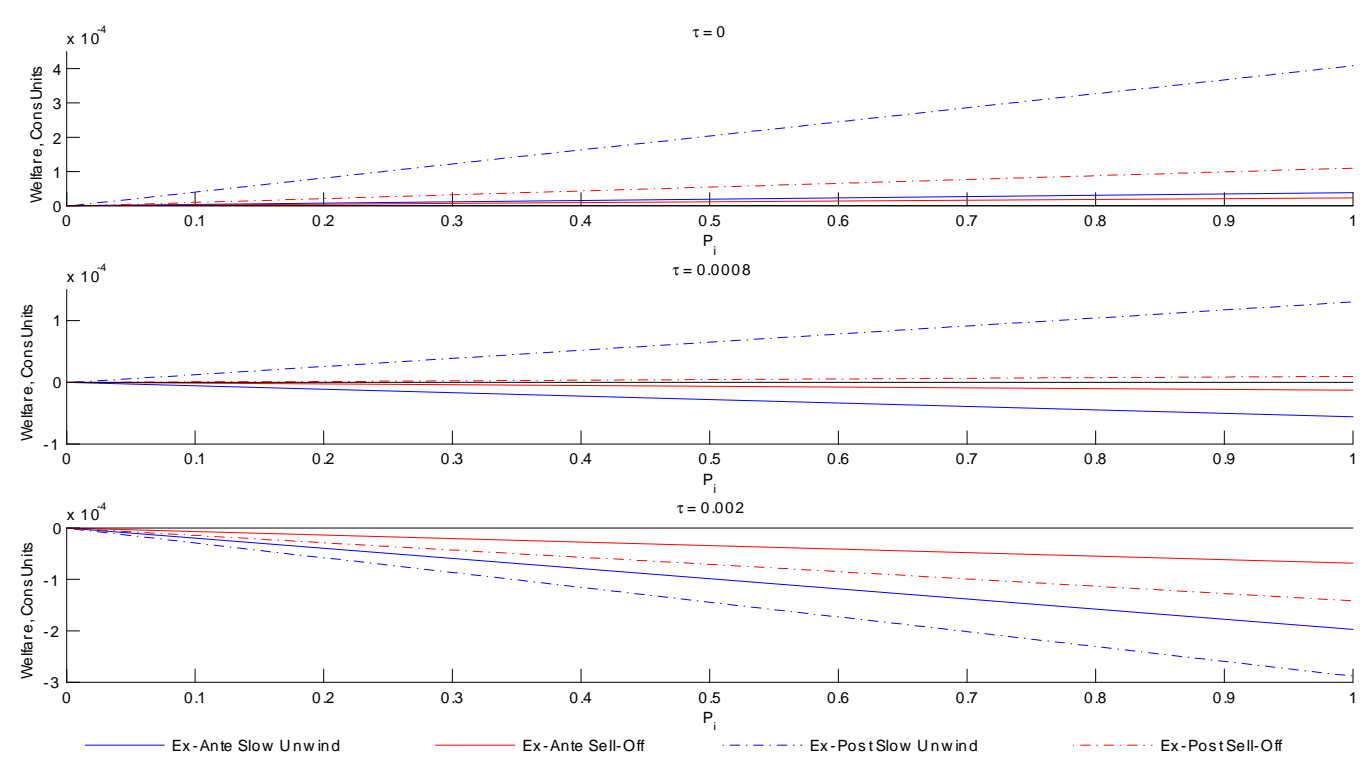

Figure 8: Welfare and Holding Duration
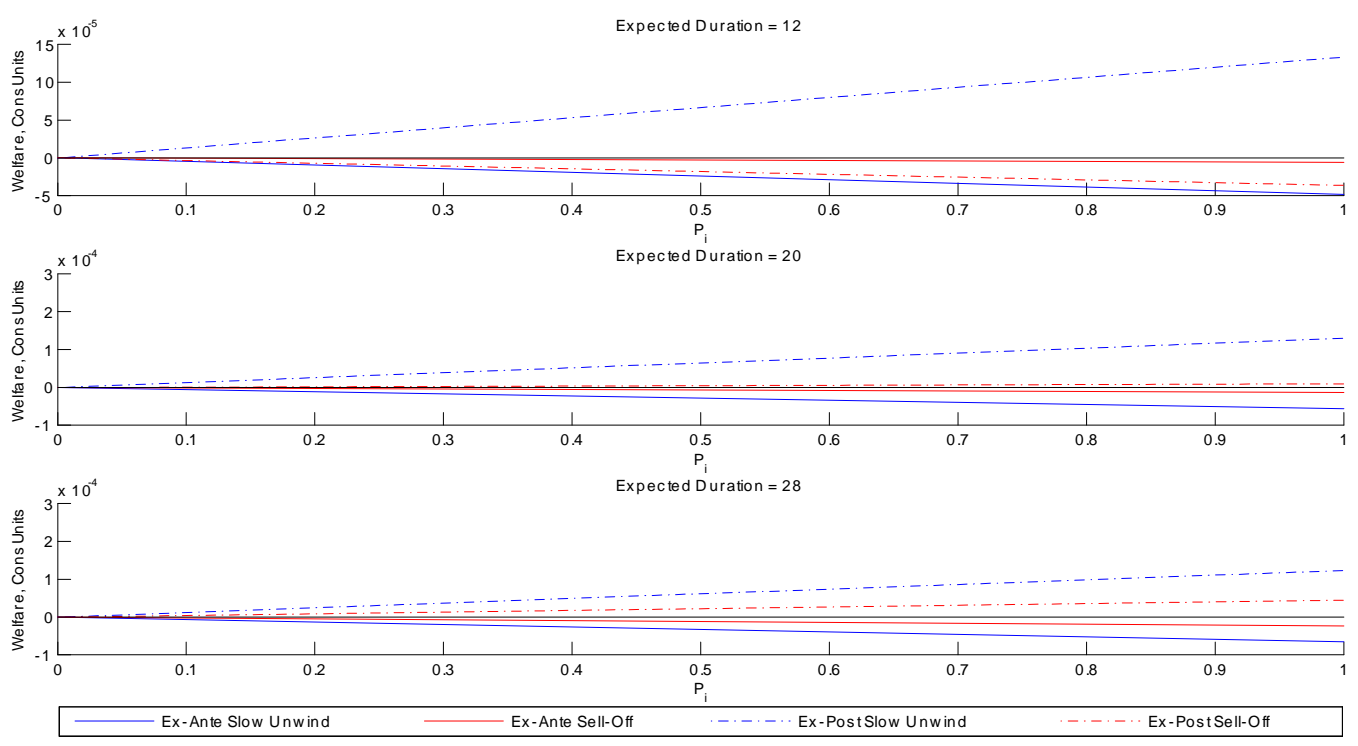